\title{
Survival and contralateral breast cancer in CHEK2 1100delC breast cancer patients: impact of adjuvant chemotherapy
}

\author{
M Kriege ${ }^{\star}, 1$, A Hollestelle ${ }^{1}$, A Jager ${ }^{1}$, P E A Huijts ${ }^{2}$, E M Berns ${ }^{3}$, A M Sieuwerts ${ }^{3}$, M E Meijer-van Gelder ${ }^{3}$, \\ J M Collée ${ }^{4}$, P Devilee ${ }^{2}$, M J Hooning ${ }^{1}$, J W M Martens ${ }^{1}$ and C Seynaeve ${ }^{1}$ \\ ${ }^{1}$ Family Cancer Clinic, Department of Medical Oncology, Erasmus MC Cancer Institute, Groene Hilledijk 301, 3075 EA Rotterdam, \\ The Netherlands; ${ }^{2}$ Department of Human Genetics, Leiden University Medical Centre, Leiden, The Netherlands; ${ }^{3}$ Department of \\ Medical Oncology, Erasmus University Medical Centre Cancer Institute, Rotterdam, The Netherlands and ${ }^{4}$ Family Cancer Clinic, \\ Department of Clinical Genetics, Erasmus University Medical Centre, Rotterdam, The Netherlands
}

Background: We assessed the sensitivity to adjuvant chemotherapy in cell cycle checkpoint kinase 2 (CHEK2) vs non-CHEK2 breast cancer patients by comparing the contralateral breast cancer incidence and distant disease-free and breast cancer-specific survival between both groups, stratified for adjuvant chemotherapy.

Methods: One Dutch hereditary non-BRCA1/2 breast cancer patient cohort $(n=1220)$ and two Dutch cohorts unselected for family history ( $n=1014$ and $n=2488$, respectively) were genotyped for CHEK2 1100delC. Hazard ratios for contralateral breast cancer, distant disease-free and breast cancer-specific death for mutation carriers vs noncarriers were calculated using the Cox proportional hazard method, stratified for adjuvant chemotherapy.

Results: The CHEK2 mutation carriers $(n=193)$ had an increased incidence of contralateral breast cancer (multivariate hazard ratio 3.97, 95\% confidence interval 2.59-6.07). Distant disease-free and breast cancer-specific survival were similar in the first 6 years in mutation carriers compared with noncarriers, but diverted as of 6 years after breast cancer diagnosis (multivariate hazard ratios and 95\% confidence intervals 2.65 (1.79-3.93) and 2.05 (1.41-2.99), respectively). No significant interaction between CHEK2 and adjuvant chemotherapy was observed.

Conclusions: The CHEK2 1100delC-associated breast cancer is associated with a higher contralateral breast cancer rate as well as worse survival measures beyond 6 years after diagnosis. No differential sensitivity to adjuvant chemotherapy was observed in CHEK2 patients.

In 2002, the cell cycle checkpoint kinase 2 (CHEK2) gene was identified as the first moderate-risk susceptibility gene for breast cancer. The CHEK2 1100delC mutation has been associated with a two- to three-fold increased risk of developing breast cancer in women (Meijers-Heijboer et al, 2002; The CHEK2-Breast Cancer Consortium, 2002; Weischer et al, 2008; Cybulski et al, 2011). The frequency of the CHEK2 1100delC mutation is relatively high in the Netherlands, being $\sim 1 \%$ in the general population, $2-4 \%$ in unselected breast cancer patients and $5-6 \%$ in breast cancer patients with a family history of breast cancer (The CHEK2-Breast Cancer Consortium, 2002; The CHEK2 Breast Cancer CaseControl Consortium, 2004; Hollestelle et al, 2010).

The CHEK2 kinase acts as a tumour suppressor and plays a critical role in DNA damage repair. Because of a compromised DNA repair mechanism, it has been hypothesised that CHEK2 mutation carriers might have an increased sensitivity to chemotherapeutic agents causing double-strand DNA breaks, such as platinum or anthracyclines (Nevanlinna and Bartek, 2006). 
Previous studies showed that CHEK2 1100delC-associated breast cancer patients had mainly oestrogen receptor (ER)-positive tumours (de Bock et al, 2006; Nagel et al, 2012; Weischer et al, 2012), and a higher incidence of contralateral breast cancer compared with noncarriers (de Bock et al, 2004; Schmidt et al, 2007; Weischer et al, 2012). In addition, a worse disease-free and overall survival has been observed in CHEK2 1100delC-associated breast cancer patients compared with patients without this mutation (de Bock et al, 2004; Schmidt et al, 2007; Weischer et al, 2012). In the overall breast cancer population, the risk of contralateral breast cancer is reduced by adjuvant chemotherapy (Bertelsen et al, 2008; Reding et al, 2010). Data on the impact of adjuvant chemotherapy on the contralateral breast cancer risk and survival of CHEK2 1100delC-associated breast cancer patients vs noncarriers have not been reported yet. If CHEK2 1100delC mutation carriers are indeed more sensitive to chemotherapy due to a defective DNA repair mechanism, the differences in contralateral breast cancer incidence and in distant disease-free and breast cancer-specific survival in CHEK2 mutation carriers compared with noncarriers would be most pronounced in breast cancer patients not treated with adjuvant chemotherapy.

In this study we therefore evaluated the contralateral breast cancer rate, distant disease-free survival and breast cancer-specific survival in breast cancer patients with the CHEK2 1100delC mutation compared with patients without this mutation, stratified for adjuvant treatment with chemotherapy.

\section{MATERIALS AND METHODS}

Three different cohorts of women with invasive early breast cancer were included in this study. Overall inclusion criteria were: age at diagnosis of first breast cancer $<80$ years, diagnosis of first breast cancer after 1970, no distant metastases at or within 3 months after primary diagnosis, no proven $B R C A 1$ or $B R C A 2$ mutation and follow-up data available.

The first cohort $(n=1220)$ consisted of breast cancer patients ascertained through the Rotterdam Family Cancer Clinic. All selected patients were tested negative for BRCA1 and BRCA2 mutations. We refer to this cohort as the 'non-BRCA1/2' cohort.

The second cohort $(n=1014$, after exclusion of 64 patients already included in the non-BRCA1/2 cohort) consisted of patients enrolled in the ORIGO study, designed to investigate the percentage of BRCA1/2 mutations in an unselected breast cancer population. This study concerned a consecutive series of breast cancer patients. Data on contralateral breast cancer rate and survival for CHEK2 mutation carriers vs non-carriers have been previously described (de Bock et al, 2004). We refer to this cohort as 'ORIGO'.

The third cohort was drawn from the Rotterdam Medical Oncology Tumour bank (RMOT) database $(n=2488$, after exclusion of 114 patients already included in the non-BRCA1/2 cohort and 1 patient already included in the ORIGO cohort). The RMOT database included breast cancer patients mainly diagnosed in the South Western region of the Netherlands from whom fresh frozen breast tumour specimens were submitted to the Erasmus MC for routine ER and progesterone receptor (PgR) measurement between 1978 and 2004. We refer to this cohort as 'RMOT'.

Part of the non-BRCA1/2 cohort (57\%) and the entire ORIGO cohort were also included in the study of Weischer et al (2012), investigating survival and contralateral breast cancer risk in CHEK2 1100delC mutation carriers. For the current study, follow-up of the patients in both cohorts has been updated to July 2010.

For all eligible patients of the three cohorts, data on patient and tumour characteristics, treatment and follow-up were collected from the medical records. The study was approved by the Institutional Review Board.
Genotyping. DNA was isolated from peripheral blood for patients from the non-BRCA1/2 and ORIGO cohorts and from freshly frozen tumour tissue for patients from the RMOT cohort (The CHEK2 Breast Cancer Case-Control Consortium, 2004; Riaz et al, 2012). The CHEK2 1100delC mutation status was determined by either allele-specific oligonucleotide hybridisation or Taqman genotyping as described earlier (Meijers-Heijboer et al, 2002; Jekimovs et al, 2005). A number of samples $(n=783)$ were analysed with both methods, showing a concordance of $100 \%$ between the two methods.

Statistical analyses. Differences in patient and tumour characteristics and types of treatment between CHEK2 1100delC mutation carriers and noncarriers were compared by $t$-test (continuous variables) or $\chi^{2}$ test (categorical variables). Events of interest were metachronous contralateral breast cancer (diagnosed $>3$ months after diagnosis of the first breast cancer), distant metastases and breast cancer-specific death. For analyses regarding metachronous contralateral breast cancer, the non-BRCA1/2 cohort was excluded, because this cohort probably is enriched with cases with bilateral breast cancer cases as contralateral breast cancer is one of the criteria for referral for genetic testing for BRCA1/2 mutations and therefore might overestimate the contralateral breast cancer incidence. Kaplan-Meier curves were constructed for contralateral breast cancer rate, distant disease-free survival and breast cancerspecific survival for CHEK2 1100delC mutation carriers and noncarriers separately. Censoring events overall were death not related to breast cancer, last medical contact or end of this study (1 July 2010), and for contralateral breast cancer rate it also included death because of breast cancer and preventive bilateral or contralateral mastectomy. Differences in outcome between CHEK2 1100delC mutation carriers and noncarriers were tested by the log rank test.

We calculated univariate and multivariate hazard ratios (HRs) and $95 \%$ confidence intervals (CIs) for the above-mentioned events for mutation carriers vs noncarriers by the Cox proportional hazard method. Models were adjusted for patient, tumour and

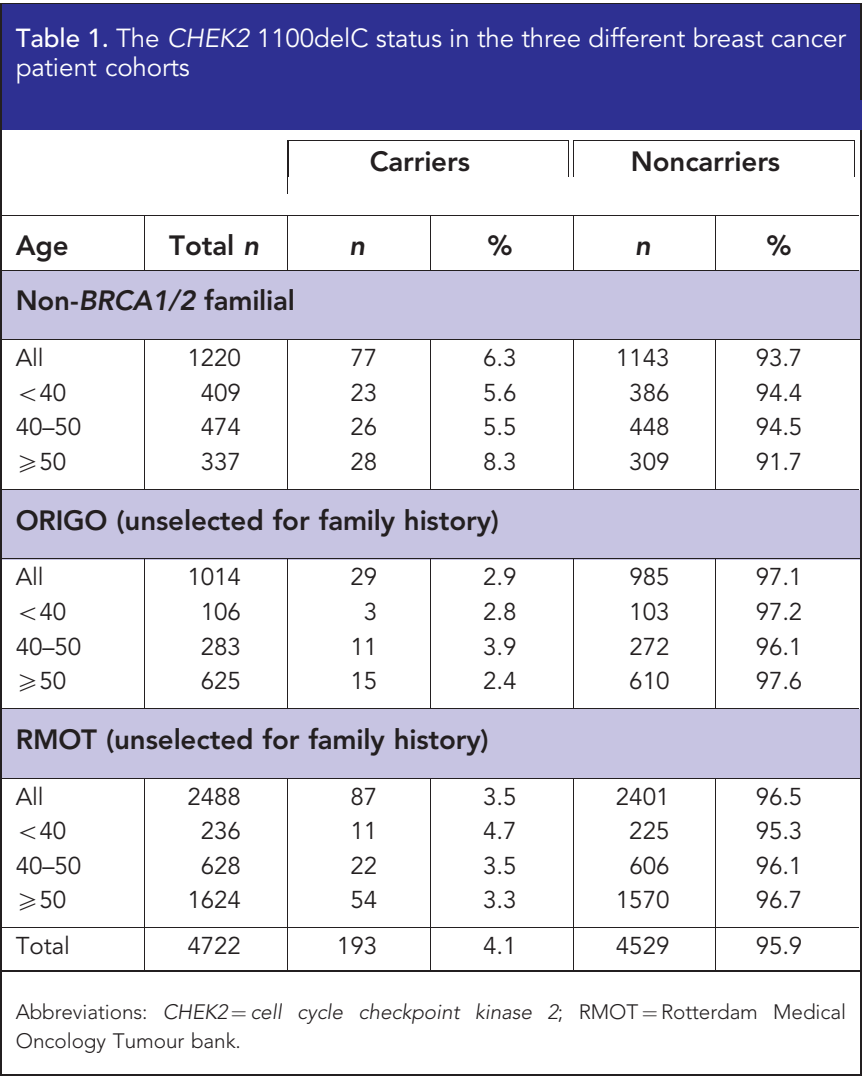


treatment factors, including age at and year of diagnosis, cohort (non-BRCA1/2, ORIGO, RMOT), tumour size (T1, T2, T3 or T4, unknown), nodal status (negative, positive, unknown), hormone receptor status (negative, positive, unknown), differentiation grade $(1,2,3$, unknown), type of surgery (lumpectomy, mastectomy, none or unknown), adjuvant chemotherapy (yes, no, unknown), adjuvant hormonal therapy (yes, no, unknown) and radiotherapy (yes, no, unknown), and the models for distant disease-free and breast cancer-specific survival also for contralateral breast cancer as time-dependent variable. Tumour ER and PgR analyses were performed by ligand binding assay or enzyme-linked immunoassay. The cutoff for ER and PgR positivity was $10 \mathrm{fmol} \mathrm{mg}^{-1}$ cytosolic protein or $\geqslant 10 \%$ immunopositive cells. A negative hormone receptor status was defined as negativity for both ER and $\mathrm{PgR}$, and a positive hormone receptor status as positivity for ER and/or PgR. Hormone receptor status was considered as unknown if information on both ER and PgR status was lacking, or in case of negative ER and unknown PgR status.

The proportional hazard assumption was assessed by using an extended Cox model with time-depending covariables. A likelihood

Table 2. Patient and tumour characteristics of cell cycle checkpoint kinase 2 (CHEK2) 1100delC mutation carriers and noncarriers

\begin{tabular}{|c|c|c|c|c|c|}
\hline & \multicolumn{2}{|c|}{ Carrier } & \multicolumn{2}{|c|}{ Noncarrier } & \multirow[b]{2}{*}{$P$-value } \\
\hline & $n$ & $\%$ & $n$ & $\%$ & \\
\hline Number of patients & 193 & & 4529 & & \\
\hline Median follow-up in years & $6.8(0.6-31.9)$ & & $7.2(0.1-38.9)$ & & \\
\hline \multicolumn{6}{|c|}{ Age at breast cancer diagnosis } \\
\hline $\begin{array}{l}\text { Median (years) } \\
\text { Mean (years) } \\
\text { Range (years) } \\
<40 \\
40-50 \\
\geqslant 50\end{array}$ & $\begin{array}{c}50.0 \\
50.1 \\
22.5-78.0 \\
37 \\
59 \\
97\end{array}$ & $\begin{array}{l}19.2 \\
30.6 \\
50.3\end{array}$ & $\begin{array}{c}51.4 \\
52.8 \\
18.7-79.9 \\
714 \\
1326 \\
2489\end{array}$ & $\begin{array}{l}15.8 \\
29.3 \\
55.0\end{array}$ & $\begin{array}{l}0.003 \\
0.14\end{array}$ \\
\hline \multicolumn{6}{|l|}{ Year of diagnosis } \\
\hline $\begin{array}{l}<1990 \\
1990-2000 \\
>2000\end{array}$ & $\begin{array}{l}58 \\
83 \\
52\end{array}$ & $\begin{array}{l}30.1 \\
43.0 \\
26.9\end{array}$ & $\begin{array}{r}1590 \\
1996 \\
943\end{array}$ & $\begin{array}{l}35.1 \\
44.1 \\
20.8\end{array}$ & 0.04 \\
\hline \multicolumn{6}{|c|}{ Synchronous contralateral breast cancer } \\
\hline $\begin{array}{l}\text { No } \\
\text { Yes } \\
\end{array}$ & $\begin{array}{r}189 \\
4 \\
\end{array}$ & $\begin{array}{r}97.9 \\
2.1 \\
\end{array}$ & $\begin{array}{r}4443 \\
86 \\
\end{array}$ & $\begin{array}{r}98.1 \\
1.9 \\
\end{array}$ & 0.87 \\
\hline \multicolumn{6}{|l|}{ T stage } \\
\hline $\begin{array}{l}\text { T1 } \\
\text { T2 } \\
\text { T3 } \\
\text { T4 } \\
\text { Unknown }\end{array}$ & $\begin{array}{r}95 \\
72 \\
11 \\
5 \\
10\end{array}$ & $\begin{array}{r}51.9 \\
39.3 \\
6.0 \\
2.7 \\
(5.2)\end{array}$ & \begin{tabular}{r|}
2074 \\
1886 \\
264 \\
168 \\
137
\end{tabular} & $\begin{array}{r}47.2 \\
42.9 \\
6.0 \\
3.8 \\
(3.0)\end{array}$ & 0.23 \\
\hline \multicolumn{6}{|l|}{$\mathrm{N}$ stage } \\
\hline $\begin{array}{l}\text { Negative } \\
1-3 \\
4+ \\
\text { Unknown }\end{array}$ & $\begin{array}{r}105 \\
35 \\
44 \\
9\end{array}$ & $\begin{array}{l}57.1 \\
19.0 \\
23.9 \\
(4.7)\end{array}$ & $\begin{array}{r}2388 \\
1096 \\
949 \\
96\end{array}$ & $\begin{array}{l}53.9 \\
24.7 \\
21.4 \\
(2.1)\end{array}$ & 0.31 \\
\hline \multicolumn{6}{|l|}{ Differentiation grade } \\
\hline $\begin{array}{l}1 \\
2 \\
3 \\
\text { Unknown }\end{array}$ & $\begin{array}{l}21 \\
52 \\
70 \\
50\end{array}$ & $\begin{array}{l}14.7 \\
36.4 \\
49.0 \\
(25.9)\end{array}$ & $\begin{array}{r}370 \\
1155 \\
2014 \\
990\end{array}$ & $\begin{array}{l}10.5 \\
32.6 \\
56.9 \\
(21.9)\end{array}$ & 0.11 \\
\hline \multicolumn{6}{|c|}{ Hormone receptor status } \\
\hline $\begin{array}{l}\text { Negative } \\
\text { Positive } \\
\text { Unknown }\end{array}$ & $\begin{array}{r}9 \\
157 \\
30\end{array}$ & $\begin{array}{r}5.5 \\
94.5 \\
(15.5)\end{array}$ & $\begin{array}{r}759 \\
3173 \\
597\end{array}$ & $\begin{array}{l}19.3 \\
80.7 \\
(13.2)\end{array}$ & $<0.001$ \\
\hline \multicolumn{6}{|l|}{ HER2/neu } \\
\hline $\begin{array}{l}\text { Negative } \\
\text { Positive } \\
\text { Unknown }\end{array}$ & $\begin{array}{l}73 \\
23 \\
97\end{array}$ & $\begin{array}{c}76.0 \\
24.0 \\
(50.2)\end{array}$ & $\begin{array}{c}1886 \\
452 \\
2191 \\
\end{array}$ & $\begin{array}{c}80.7 \\
19.3 \\
(48.3)\end{array}$ & 0.26 \\
\hline
\end{tabular}


ratio test was used to test whether an extended model was significantly different compared with the proportional hazard model. The extended models for CHEK2 and tumour size were significant for both distant metastases $(P=0.003$ and $P=0.002$, respectively) and breast cancer-specific death $(P=0.02$ and $P=0.04)$, indicating that the hazards for distant metastases and breast cancer-specific death by CHEK2 1100delC and tumour size were not proportional over time. Because the survival curves for distant disease-free and breast cancer-specific survival for CHEK2 mutation carriers and noncarriers were similar over the first 6 years, but started to diverge after 6 years (Figure 2A and D), we chose for an extended Cox model with tumour size as timedependent variable and that contains a heaviside function (Kleinbaum and Klein, 2005), together with the CHEK2 1100delC variable, with a cutoff point of 6 years. The corresponding model then provided two hazard ratios for CHEK2 1100delC, one for the first 6 years and one for beyond 6 years after breast cancer diagnosis.

Analyses for contralateral breast cancer distant disease-free and breast cancer-specific survival were stratified for adjuvant treatment with chemotherapy (yes/no). Analyses for distant disease-free survival were also stratified for type of adjuvant chemotherapy (anthracycline-based/nonanthracycline-based) and adjuvant hormonal therapy (yes/no).

Interaction terms between CHEK2 1100delC mutation status and administration of adjuvant chemotherapy (yes/no) for the different end points were calculated. In addition, the prognostic impact of age at diagnosis, tumour size, nodal status, ER status, chemotherapy and hormonal therapy were analysed separately for CHEK2 1100delC and non-CHEK2 patients.

All analyses were performed using SPSS (version 20.0; SPSS, Inc., Chigago, IL, USA) and Stata (version 12; Stat Corporation, College Station, TX, USA). A two-sided $P<0.05$ was considered as statistically significant.

\section{RESULTS}

In total, $193(4.1 \%)$ of the 4722 included female breast cancer patients tested positive for the CHEK2 1100delC mutation (Table 1). The percentage of CHEK2 1100delC mutations was highest in the non-BRCA1/2 cohort $(6.3 \%, n=77)$ vs $2.9 \%$ $(n=29)$ in the ORIGO and $3.5 \%(n=87)$ in the RMOT cohort, respectively.

Patient and tumour characteristics of the 193 CHEK2 1100delC mutation carriers and the 4529 non-carriers are shown in Table 2. The median follow-up time was 6.8 years for mutation carriers and 7.2 years for noncarriers. The CHEK2 1100delC-associated breast cancer patients were significantly younger at diagnosis than the noncarriers (median 50.0 vs 51.4 years). In addition, mutation carriers were more often diagnosed with breast cancer after 2000 (26.9\% vs 20.8\%), probably reflecting the higher percentage of CHEK2 1100delC mutation carriers in the non-BRCA1/2 cohort, as patients in this cohort were more often diagnosed after 2000 (51\%) compared with patients from the RMOT cohort $(<1 \%)$ and ORIGO cohort (37\%; data not shown in tables). Breast cancers in mutation carriers were more often hormone receptor positive compared with cancers in noncarriers $(94.5 \%$ vs $80.7 \%)$. No significant differences in tumour size, nodal status, differentiation grade and her2 expression were observed between CHEK2 1100 delC mutation carriers and noncarriers.

Types of treatment are shown in Table 3. Significantly less CHEK2-associated breast cancer patients received radiotherapy compared with the noncarriers $(62.0 \%$ vs $71.3 \%)$. This observation could not be explained by differences in surgical therapy (lumpectomy $v s$ mastectomy), TN stage or age at diagnosis, but might be partly explained by differences in the year of diagnosis between the two groups (see Table 2). Adjuvant chemotherapy was administered to $31 \%$ of the patients, mainly consisting of anthracycline-containing regimens, and $24 \%$ of the patients received adjuvant endocrine therapy, mainly consisting of tamoxifen. This was not significant different between CHEK2 mutation carriers and noncarriers.

Contralateral breast cancer risk. The incidence of metachronous contralateral breast cancer was higher in CHEK2 1100delC mutation carriers than in noncarriers, with a 10-year risk of $28.9 \%$ vs $8.5 \%$, respectively (Table 4 and Figure 1). In a multivariate analysis, the risk of contralateral breast cancer remained higher in mutation carriers compared with noncarriers (HR 3.97, 95\% CI 2.59-6.07).

If stratified for adjuvant chemotherapy, the increased contralateral breast cancer rate for CHEK2 1100delC-associated breast cancer patients was observed in both the group treated with and without chemotherapy (HR multivariate 6.95, 95\% CI 3.21-15.00 and 3.15, 95\% CI 1.86-5.35, respectively). Although the HR was higher for

\begin{tabular}{|c|c|c|c|c|c|}
\hline & \multicolumn{2}{|c|}{ Carrier } & \multicolumn{2}{|c|}{ Noncarrier } & \\
\hline & $n$ & $\%$ & $n$ & $\%$ & $P$-value \\
\hline \multicolumn{6}{|c|}{ Surgical therapy } \\
\hline None & 0 & 0 & 10 & 0.2 & 0.80 \\
\hline Lumpectomy & 88 & 47.1 & 2087 & 46.4 & \\
\hline Mastectomy & 99 & 52.9 & 2405 & 53.4 & \\
\hline Unknown & 6 & & 27 & & \\
\hline
\end{tabular}

Adjuvant systemic therapy

None

Only hormonal therapy

Chemo- and hormonal therapy

Unknown

(Neo)-adjuvant chemotherapy

\begin{tabular}{|l|r|r|r|r|l}
\hline None & 129 & 69.4 & 3089 & 69.0 & 0.41 \\
Anthracyclines & 38 & 20.4 & 838 & 18.7 & \\
Anthracyclines/taxanes & 0 & 0 & 68 & 1.5 & \\
Other & 16 & 8.6 & $435^{\mathrm{a}}$ & 9.7 & \\
Unknown type & 3 & 1.6 & 45 & 1.0 & \\
Unknown if treated & 7 & & 54 & &
\end{tabular}

Adjuvant hormonal therapy

\begin{tabular}{|l|r|r|r|r|c|}
\hline None & 143 & 77.3 & 3392 & 76.0 & 0.46 \\
LHRH/ other & 6 & 3.2 & $84^{\mathrm{b}}$ & 1.9 & \\
Tamoxifen & 33 & 17.8 & 812 & 18.2 & \\
Aromatase inhibitor & 1 & 0.5 & 29 & 0.6 & \\
Sequential tamoxifen/aromatase & 2 & 1.1 & 120 & 2.7 & \\
inhibitor & & & & & \\
Unknown type & 0 & 0 & 27 & 0.6 & \\
Unknown if treated & 8 & & 65 & & \\
\hline Radiotherapy & 73 & 38.0 & 1298 & 28.7 & 0.006 \\
No & 119 & 62.0 & 3220 & 71.3 & \\
Yes & 1 & & 11 & & \\
Unknown & &
\end{tabular}

Abbreviations: $\quad C H E K 2=$ cell cycle checkpoint kinase 2; $L H R H=$ luteinising-hormonereleasing hormone.

${ }^{a_{F}}$ our patients received taxanes.

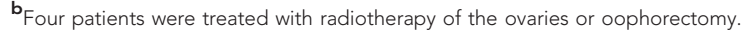


patients treated with adjuvant chemotherapy, no significant interaction between the CHEK2 1100delC mutation and adjuvant chemotherapy was observed (HR for interaction 2.15; $P=0.10$; not shown in Tables). Stratifying for adjuvant endocrine therapy was not possible because only 19 CHEK2 1100delC-associated breast cancer patients were treated with hormonal therapy. No contralateral breast cancers were observed in these 19 patients.

Survival. The data regarding distant disease-free survival are shown in Table 5 and Figure $2 \mathrm{~A}-\mathrm{C}$ and regarding breast cancerspecific survival in Table 5 and Figure 2D-F. The Kaplan-Meier curves showed a nonsignificant decreased distant disease-free $(P=0.06)$ and breast cancer-specific survival $(P=0.14)$ for CHEK2-associated patients compared with non-CHEK2 patients (Figure 2A and D).

As can be observed in the Kaplan-Meier curves, the distant disease-free (Figure 2A) and breast cancer-specific survival (Figure 2D) were similar over the first 6 years after breast cancer diagnosis for CHEK2 1100delC mutation carriers and noncarriers and started to diverge after 6 years. In the first 6 years after breast cancer diagnosis, the multivariate hazard ratios for CHEK2 vs nonCHEK2 breast cancer patients were not significant for distant disease-free $(1.08 ; 95 \%$ CI $0.83-1.42)$ and breast cancer-specific survival $(1.00,95 \%$ CI $0.71-1.41)$. Survival outcomes beyond 6 years after breast cancer diagnosis, however, were significantly worse for CHEK2 mutation carriers compared with noncarriers. Multivariate HRs for the period beyond 6 years after breast cancer diagnosis were 2.65 (95\% CI 1.79-3.93) for distant disease-free and 2.05 (95\% CI 1.41-2.99) for breast cancer-specific survival, respectively.

If we stratified our analyses for adjuvant chemotherapy, a significantly worse distant disease-free $(P=0.002)$ and a trend for a worse breast cancer-specific survival $(P=0.05)$ were observed for CHEK2-associated compared with non-CHEK2-associated breast cancer patients in the chemotherapy group (Figure $2 \mathrm{C}$ and $\mathrm{F}$ ) that was not observed in the group not treated with chemotherapy ( $P=0.52$ and $P=0.40$, respectively, Figure $2 \mathrm{~B}$ and $\mathrm{E})$. However, in both treatment groups, the group treated with and the group treated without adjuvant chemotherapy, we observed in the first 6 years after breast cancer diagnosis no significant differences in distant disease-free survival between CHEK2 mutation carries and noncarriers (HR multivariate 1.41, 95\% CI 0.91-2.16 and HR multivariate 0.98 , 95\% CI 0.69-1.38, respectively; Table 5), whereas beyond 6 years after breast cancer diagnosis, a significantly worse distant disease-free survival in CHEK2 mutation carriers compared with noncarriers was observed for both the adjuvant chemotherapy group (HR 4.54, 95\% CI 2.41-8.65) and the group without adjuvant chemotherapy $(2.31,95 \%$ CI 1.39-3.83). Although the HRs were higher in the adjuvant chemotherapy group compared with the group without adjuvant chemotherapy, no significant interaction was observed between CHEK2 1100delC and adjuvant chemotherapy (HR interaction $1.51 ; P=0.08$; data not shown in tables).

If analysing patients treated with anthracycline-based chemotherapy and nonanthracycline-based chemotherapy separately, we observed in both groups a significantly worse distant disease-free survival beyond 6 years after breast cancer diagnosis for CHEK2 mutation carriers compared with noncarriers (HR multivariate 4.16, 95\% CI 1.69-10.22 and 4.73 95\% CI 1.85-12.09, respectively; Table 5).

In addition, stratifying for treatment with hormonal therapy (yes/no) had no major impact on the hazard ratio for disease-free survival. The CHEK2-associated breast cancer patients had a significantly worse distant disease-free survival than noncarriers beyond 6 years after diagnosis, independently of treatment with adjuvant hormonal therapy (HR 3.24, 95\% CI 1.16-9.03) or without adjuvant hormonal therapy (HR 2.88, 95\% CI 1.88-4.41; Table 5).

For breast cancer-specific survival a similar phenomenon was observed; only beyond 6 years after breast cancer diagnosis a significantly worse breast cancer-specific survival was observed for CHEK2 mutation carriers $v s$ noncarriers in both adjuvant chemotherapy groups (i.e., the group treated with and without adjuvant chemotherapy). In the first 6 years after breast cancer diagnosis, we observed no significant difference in breast cancerspecific survival between $C H E K 2$ mutation carriers and noncarriers (Figure 2D-F and Table 5).

In Table 6, multivariate HRs with respect to breast cancerspecific survival are presented for several prognostic factors, separately for CHEK2 and non-CHEK2 patients. Age at diagnosis, tumour size and nodal status appeared to be prognostic factors in both groups, although the prognostic value of age at diagnosis was not significant in the CHEK2 group. Interestingly, ER status appeared only to be a prognostic factor in the non-CHEK2 group

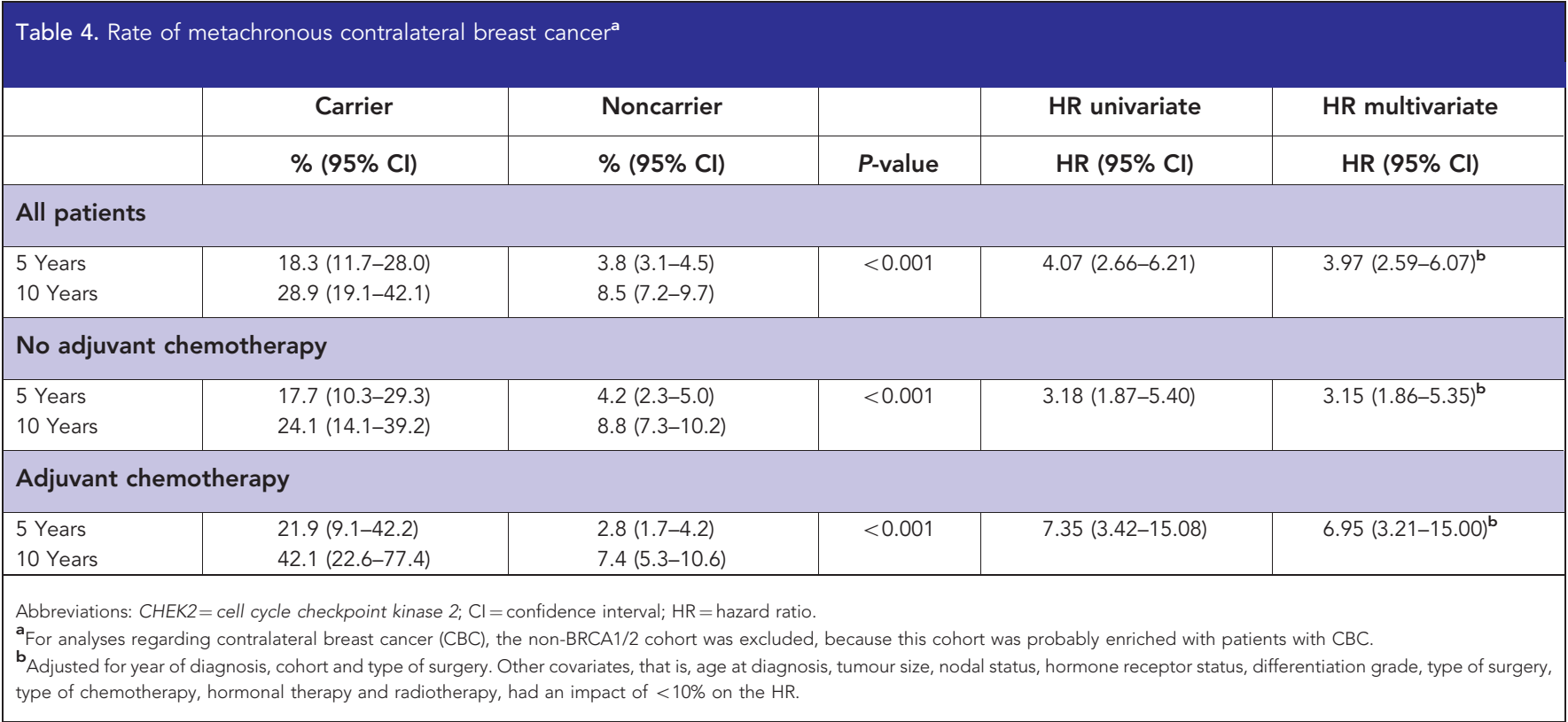


(HR 0.58, 95\% CI 0.45-0.75) and not in the CHEK2 group (HR 1.11, 95\% CI 0.43-2.84). Administration of adjuvant chemotherapy (HR $0.70 \quad 95 \%$ CI $0.35-1.41$ ) and of adjuvant hormonal therapy (HR $0.62,95 \%$ CI $0.30-1.28$ ) had a nonsignificant favourable effect on breast cancer-specific survival in the CHEK2 group.

A

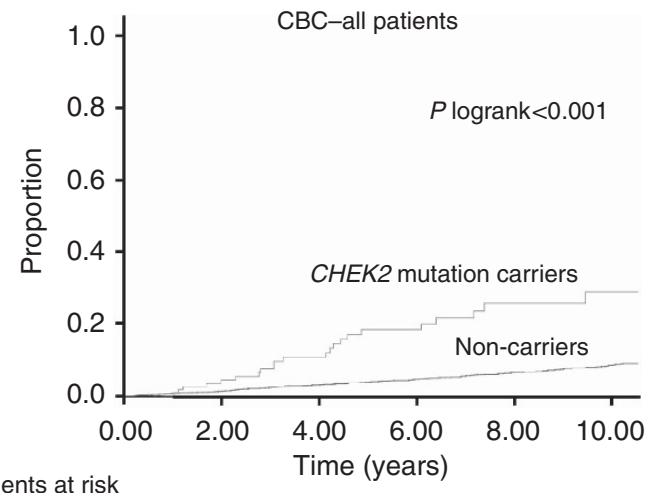

Patients at risk

$\begin{array}{lccc}\text { Carriers } & 124^{*} & 60 & 20 \\ \text { Non-carriers } & 3490^{*} & 2065 & 836 \\ \text { Cumulative } & \text { number of events } & & \\ \text { Carriers } & 0 & 17 & 22 \\ \text { Non-carriers } & 0 & 105 & 175\end{array}$

B

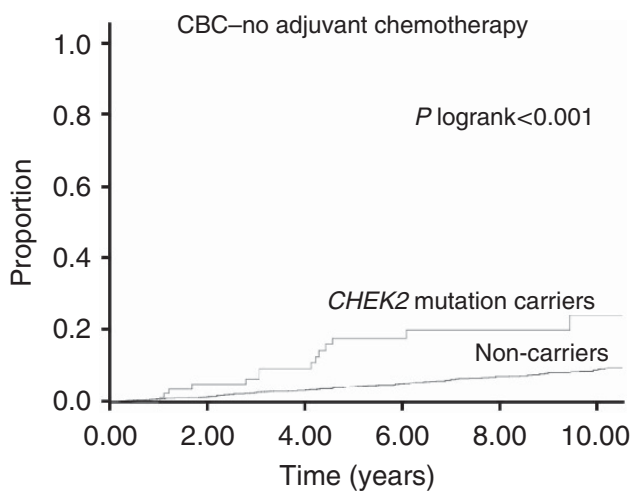

Patients at risk

$\begin{array}{llcc}\text { Carriers } & 90 \# & 46 & 16 \\ \text { Non-carriers } & 2614 \# & 1544 & 625 \\ \text { Cumulative } & \text { number of events } & & \\ \text { Carriers } & 0 & 12 & 14 \\ \text { Non-carriers } & 0 & 86 & 139\end{array}$

C

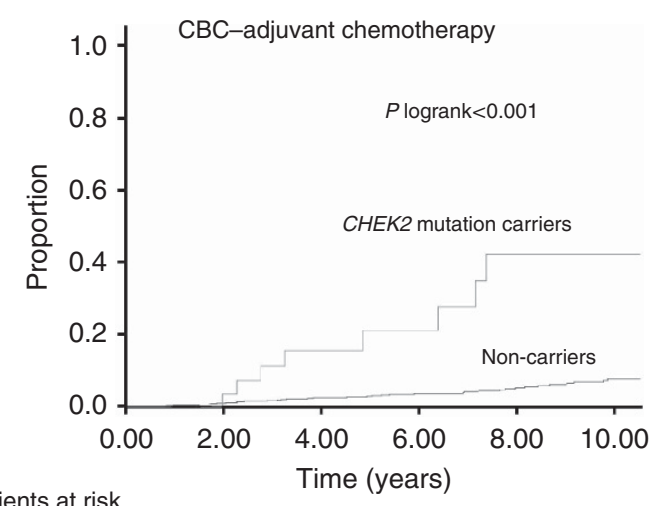

Patients at risk

$\begin{array}{lccc}\text { Carriers } & 33 \# & 14 & 3 \\ \text { Non-carriers } & 872 \# & 520 & 209 \\ \text { Cumulative } & \text { number of events } & & \\ \text { Carriers } & 0 & 5 & 86 \\ \text { Non-carriers } & 0 & 19 & 36\end{array}$

\section{DISCUSSION}

In this study, we observed a worse distant disease-free and breast cancer-specific survival for CHEK2 1100delC-associated compared with noncarrier patients, becoming apparent beyond 6 years after breast cancer diagnosis. Furthermore, we confirmed the higher incidence of contralateral breast cancer in breast cancer patients carrying the CHEK2 1100delC mutation, as observed in earlier studies (de Bock et al, 2004; Schmidt et al, 2007; Weischer et al, 2012). Both observations were not influenced by chemotherapy, suggesting no differential efficacy of chemotherapy in CHEK2 1100delC mutation carriers.

Interestingly, the worse distant disease-free and breast cancerspecific survival in CHEK2 1100delC mutation carriers was only observed beyond 6 years after breast cancer diagnosis, rather than immediately after breast cancer diagnosis. Although earlier studies also observed or suggested a worse (distant disease-free) survival in CHEK2 1100delC mutation carriers (de Bock et al, 2004; Schmidt et al, 2007; Weischer et al, 2012), none of these studies showed the phenomenon that we observed. In view of these discordant results, we further performed analyses in the three patient cohorts, and found that the trend for a worse distant disease-free and breast cancer-specific survival beyond 6 years was only observed in the RMOT cohort, whereas in the other two cohorts the survival became worse as of diagnosis (significant for the ORIGO cohort and nonsignificant for the non-BRCA1/2 cohort; data not shown). A reason for this different observation in the RMOT compared with the non-BRCA1/2 and ORIGO cohorts might be different patient characteristics in the RMOT cohort, such as the higher age at diagnosis (median 55 years compared with 44 and 52 years, respectively) and earlier diagnose years, resulting in a lower percentage of patients treated with adjuvant chemotherapy (19\% vs $52 \%$ and $37 \%$, respectively) and adjuvant hormonal therapy (14\% vs $36 \%$ and $35 \%$, respectively) and other types of treatment (more often CMF and less often anthracycline-based or taxane-based regimens). As adjuvant hormonal therapy is generally given for a period of 5 years, it can be hypothesised that the worse survival beyond 6 years in CHEK2-associated breast cancer patients might be an effect of the hormonal therapy. However, evidence for this hypothesis is not found in this study as we observed in both groups (i.e., the group treated with and the group treated without adjuvant hormonal therapy) a worse survival in CHEK2 mutation carriers compared with noncarriers more than 6 years after breast cancer diagnosis. It can also be hypothesised that the worse distant disease-free and breast cancer-specific survival for CHEK2 mutation carriers after 6 years is caused by the higher incidence of contralateral breast cancer in this group. However, this worse distant disease-free and breast cancer-specific survival remained if we censored at time of metachronous contralateral breast cancer and/or local recurrences (data not shown) and if we included contralateral breast cancer as time-dependent covariable in the extended Cox models, indicating that the observed worse survival measures are not only due to the higher incidence of contralateral breast cancer and/or local recurrences in the CHEK2 group. As the

Figure 1. Contralateral breast cancer rate for CHEK2-positive (green line) and CHEK2-negative patients (blue line) in (A) all patients, (B) patients not treated with systemic therapy and (C) patients treated with systemic therapy. *Patients with synchronous contralateral breast cancer and patients from the non-BRCA1/2 cohort were excluded for this analysis regarding metachronous contralateral breast cancer. \# In (B and C), stratified for adjuvant chemotherapy, one additional carrier and four noncarriers for whom treatment with adjuvant chemotherapy was unknown were excluded. The full colour version of this figure is available at British Journal of Cancer online. 


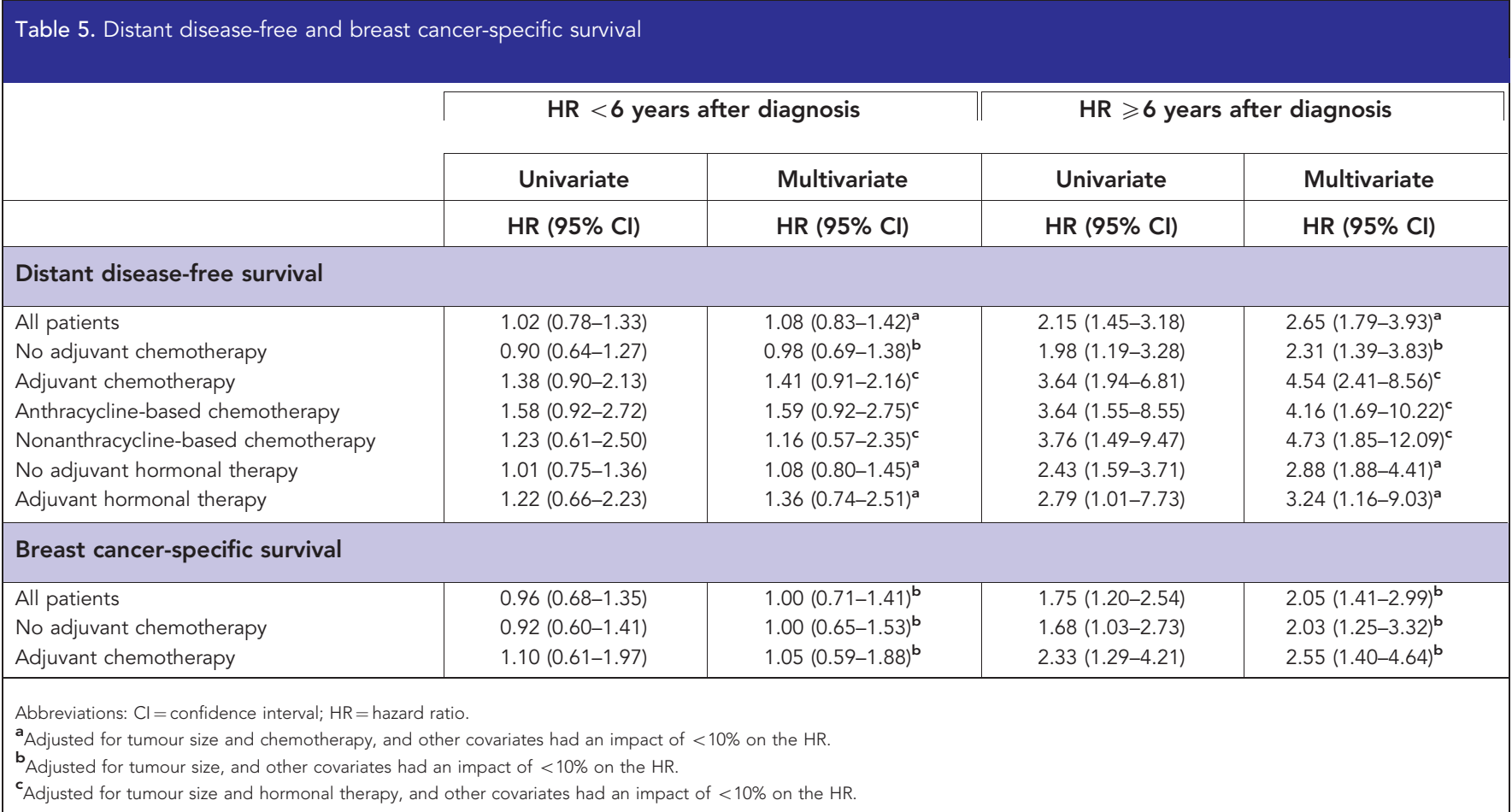

worse distant disease-free and breast cancer-specific survival cannot be explained by a reduced sensitivity to systemic therapy and by the higher incidence of contralateral breast cancer, we suppose that a different tumour biology might play a role. More research is needed into tumour biology of CHEK2 breast cancers.

The CHEK2 kinase acts as a tumour suppressor and plays a critical role in DNA damage repair. In response to double-strand DNA breaks, CHEK2 is activated by ataxia telangiectasia mutated (ATM) and involved in cell cycle control, DNA repair and apoptosis. The CHEK2 kinase phosphorylates TP53 and BRCA1, whereupon BRCA1 represses the nonhomologous end-joining pathway and activates the homologous recombination repair pathway (Nevanlinna and Bartek, 2006; Tung and Silver, 2011; Roeb et al, 2012). Based on the role of CHEK2 kinase in activating the repair mechanism of double-strand DNA breaks and the role of CHEK2 in the coordination of the mitotic spindle assembly, we hypothesised that CHEK2 1100delC mutation carriers might be more sensitive to chemotherapy. For BRCA1-associated breast cancer patients, there is growing evidence from in vitro studies on BRCA1-deficient cells and retrospective clinical studies on BRCA1 mutation carriers suggesting a higher sensitivity to chemotherapeutic agents causing double-strand DNA breaks, such as platinum or anthracyclines (Kriege et al, 2009; Bayraktar and Gluck, 2012). However, the results found in the current study do not support the hypothesis that CHEK2 mutation carriers have an increased sensitivity to chemotherapy, neither for anthracyclinebased regimens nor for nonanthracycline-based regimens. In contrast, the observations on the worse distant disease-free and breast cancer-specific survival and the higher contralateral breast cancer rate in CHEK2 mutation carriers being most pronounced in the group treated with chemotherapy suggest that CHEK2 mutation carriers are rather less than more sensitive to chemotherapy compared with noncarrier breast cancer patients. However, as the interaction between CHEK2 and adjuvant chemotherapy is not significant, we cannot prove a decreased sensitivity to adjuvant chemotherapy in CHEK2 breast cancer patients. It might be that differences in patient and tumour characteristics between the groups treated with and without adjuvant chemotherapy may have influenced the results of the analyses stratified for adjuvant chemotherapy. Patients treated with adjuvant chemotherapy were younger at diagnosis, were more often diagnosed after 2000 (anthracycline-based chemotherapy being common), had a larger tumour size, had more often node positive and hormone receptor negative tumours and were more often treated with mastectomy and hormonal therapy than patients not treated with adjuvant chemotherapy. It might be that especially younger or node-positive CHEK2-associated breast cancer patients have a worse prognosis compared with noncarriers.

The increased risk of contralateral breast cancer in CHEK2 1100delC mutation carriers was observed in patients treated with adjuvant chemotherapy as well as in patients not receiving adjuvant chemotherapy. A factor to take into account hereby is radiotherapy, as it was suggested that CHEK2 mutation carriers might be more sensitive to ionising radiation (Broeks et al, 2004, 2007; Mellemkjaer et al, 2008). However, in multivariate analyses we found an increased risk of contralateral breast cancer in both patients treated with (HR 4.12 95\% CI 2.49-6.83) and without radiotherapy (HR 3.17 95\% CI 1.36-7.35; data not shown).

The strengths of our study include the relatively large sample size, the known tumour and treatment data and the homogeneous population from one country. To our knowledge, this is in fact the largest study on survival in CHEK2 1100delC breast cancer patients with available treatment data enabling to investigate the effect of adjuvant chemotherapy in this data set.

We are however aware of some limitations. First, this is a retrospective study and consequently treatment was provided on indication, according to the Dutch guidelines existing for the respectively treatment years. Although treatment guidelines have changed over time, in general, patients with the worst prognosis (based on age at diagnosis and tumour stage/characteristics) received adjuvant chemotherapy. This probably is the reason why patients receiving adjuvant chemotherapy had a worse distant disease-free survival (median 6.5 and 15.0 years for CHEK2 mutation carriers and noncarriers, respectively; Figure 2C) compared with patients not receiving adjuvant chemotherapy (11.0 and 16.8 years for mutation carriers and noncarriers, respectively; Figure $2 \mathrm{~B}$ ).

Another possible limitation is longevity bias in the non-BRCA1/2 group, developed by selection of preferably long-living patients 


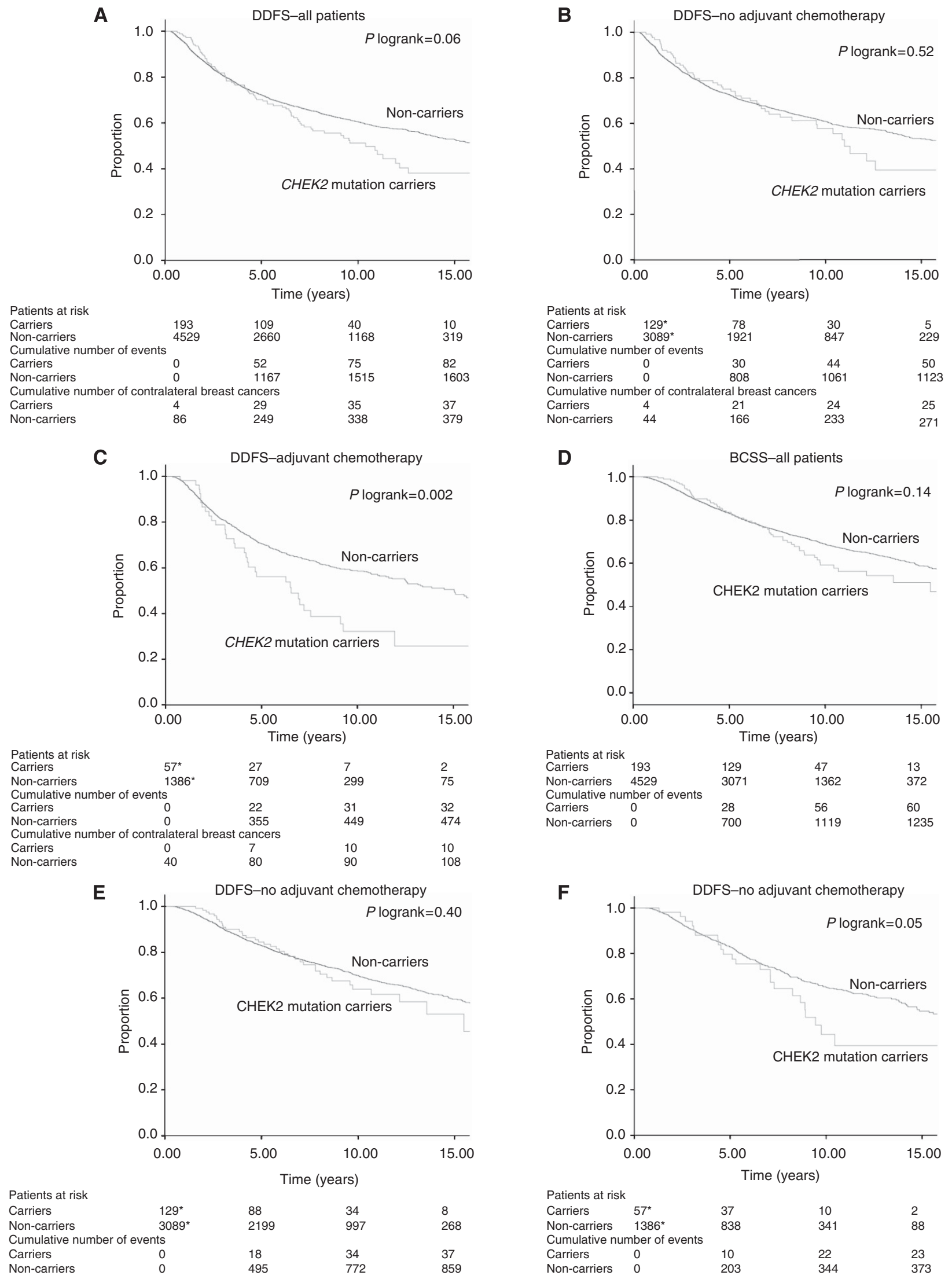

Figure 2. Distant disease-free survival for CHEK2-positive (green line) and CHEK2-negative patients (blue line) in (A) all patients, (B) patients not treated with adjuvant chemotherapy and (C) patients treated with adjuvant chemotherapy, and breast cancer-specific survival for $\mathrm{CHEK2-}$ positive (green line) and CHEK2-negative patients (blue line) in (D) all patients, (E) patients not treated with adjuvant chemotherapy and (F) patients treated with adjuvant chemotherapy. ${ }^{*}$ In (B, C, E and F) stratified for adjuvant chemotherapy, an additional 7 carriers and 54 noncarriers for whom treatment with adjuvant chemotherapy was unknown were excluded. 


\begin{tabular}{|c|c|c|}
\hline & Carrier & Noncarrier \\
\hline & HR (95\% Cl) & $\mathrm{HR}(95 \% \mathrm{Cl})$ \\
\hline \multicolumn{3}{|l|}{ Age at diagnosis } \\
\hline Per year older & $0.99(0.97-1.01)$ & $0.99(0.99-0.996)$ \\
\hline \multicolumn{3}{|l|}{ Tumour size } \\
\hline $\begin{array}{l}\text { T1 } \\
\text { T2, } 3 \text { and } 4 \\
\text { Tumour size } \times \text { time (in years) }\end{array}$ & $\begin{array}{c}1 \\
4.29(2.34-7.87)\end{array}$ & $\begin{array}{c}1 \\
2.46(1.98-3.06) \\
0.95(0.92-0.98)\end{array}$ \\
\hline \multicolumn{3}{|l|}{ Nodal status } \\
\hline $\begin{array}{l}\text { Negative } \\
\text { Positive }\end{array}$ & $\begin{array}{c}1 \\
2.28(1.17-4.46)\end{array}$ & $\begin{array}{c}1 \\
2.72(2.36-3.15)\end{array}$ \\
\hline \multicolumn{3}{|l|}{ ER status } \\
\hline $\begin{array}{l}\text { Negative } \\
\text { Positive }\end{array}$ & $\begin{array}{c}1 \\
1.11(0.43-2.84)\end{array}$ & $\begin{array}{c}1 \\
0.58(0.45-0.75)\end{array}$ \\
\hline \multicolumn{3}{|l|}{ Chemotherapy } \\
\hline $\begin{array}{l}\text { No } \\
\text { Yes }\end{array}$ & $\begin{array}{c}1 \\
0.70(0.35-1.41)\end{array}$ & $\begin{array}{c}1 \\
0.68(0.58-0.80)\end{array}$ \\
\hline \multicolumn{3}{|l|}{ Hormonal therapy } \\
\hline $\begin{array}{l}\text { No } \\
\text { Yes }\end{array}$ & $\begin{array}{c}1 \\
0.62(0.30-1.28)\end{array}$ & $\begin{array}{c}1 \\
0.89(0.76-1.05)\end{array}$ \\
\hline
\end{tabular}

who were tested for BRCA1/2 mutations (long) after their breast cancer diagnosis. After stratifying for cohort, we indeed observed the longest survival within the non-BRCA1/2 cohort. However, we also performed left-truncated analyses, and the results were similar as those from the initial analyses, with a worse distant disease-free and breast cancer-specific survival beyond 6 years after diagnosis for CHEK2 mutation carriers compared with noncarriers (data not shown).

Finally, genetic testing for CHEK2 1100delC within the RMOT cohort was performed on DNA isolated from tumour tissue and not from peripheral blood. It is possible that some germline CHEK2 1100delC mutations were missed because the mutant CHEK2 allele was lost in the tumour instead of the wild-type allele (Sodha et al, 2002; Kilpivaara et al, 2003). Moreover, a detected CHEK2 1100delC mutation in the tumour might have been acquired somatically, being different from a germline mutation. Importantly, there were no discrepancies in DNA analyses test results of CHEK2 status observed when comparing blood and tumour sample test of 115 patients.

Currently, genotyping for CHEK2 is not yet performed at genetic testing for breast cancer as it is not considered to have clinical consequences. Moreover, implementation of CHEK2 genotyping (and especially presymptomatic testing of relatives) is complicated by the observation that in breast cancer families the breast cancer risk does not segregate completely with the presence or absence of the 1100delC mutation (The CHEK2 Breast Cancer Case-Control Consortium, 2004). However, the high incidence of contralateral breast cancer in CHEK2 1100delC mutation carriers found in the current study (10-year risk 24.1\%) and in earlier studies is comparable to the incidence of contralateral breast cancer that we observed in BRCA1 and BRCA2 mutation carriers in an earlier study (10-year risk 25\% and 20\%, respectively) (Brekelmans et al, 2006) and in line with observations of other groups (10-year risk ranging between 13 and 37\%) (Haffty et al, 2002; Metcalfe et al, 2004; Robson et al, 2005; Pierce et al, 2006; Graeser et al, 2009; van der Kolk et al, 2010). Based on this increased contralateral breast cancer rate, affected BRCA1/2 mutation carriers have a more intensive follow-up scheme for contralateral breast cancer detection including MRI or can opt for a riskreducing contralateral mastectomy, even though it is unknown whether such a risk-reducing contralateral mastectomy can improve survival (Tung, 2011). In our opinion, this follow-up regimen should also be offered to CHEK2 1100delC mutation carriers after breast cancer diagnosis. In addition, as the population frequency of the CHEK2 1100delC mutation in the Netherlands is high, it may be relevant to discuss the implementation of genotyping for CHEK2 in breast cancer patients. Moreover, genetic testing for CHEK2 1100delC and may be other variants may also be considered in other populations where the mutation frequency is relevantly high such as Finland, Sweden, United Kingdom and North America (Hollestelle et al, 2010).

In conclusion, CHEK2 1100 delC mutation carriers had a significantly higher incidence of contralateral breast cancer compared with noncarriers that may have consequences for follow-up strategies in clinical practice. Distant disease-free and breast cancer-specific survival were similar over the first 6 years after diagnosis, but became worse beyond 6 years after diagnosis for CHEK2 1100delC mutation carriers compared with noncarrier BC patients. No significant interaction between adjuvant chemotherapy and a CHEK2 1100delC mutation was observed regarding contralateral breast cancer or distant disease-free survival.

\section{ACKNOWLEDGEMENTS}

We thank Jannet Blom, Ellen Crepin and Petra Bos for data management, Bahar Ozturk, Vanja de Weerd, Anne van Galen and Cliff Maasbach for technical assistance and Professor JA Foekens for his valuable comments on the manuscript. This study is supported by the Dutch Cancer Society (grant DDHK 2009-4318).

\section{CONFLICT OF INTEREST}

The authors declare no conflict of interest.

\section{REFERENCES}

Bayraktar S, Gluck S (2012) Systemic therapy options in BRCA mutationassociated breast cancer. Breast Cancer Res Treat 135: 355-366.

Bertelsen L, Bernstein L, Olsen JH, Mellemkjaer L, Haile RW, Lynch CF, Malone KE, Anton-Culver H, Christensen J, Langholz B, Thomas DC, Begg CB, Capanu M, Ejlertsen B, Stovall M, Boice JD, Shore RE, Bernstein JL (2008) Effect of systemic adjuvant treatment on risk for contralateral breast cancer in the Women's Environment, Cancer and Radiation Epidemiology Study. J Natl Cancer Inst 100: 32-40.

Brekelmans CT, Seynaeve C, Menke-Pluymers M, Bruggenwirth HT, Tilanus-Linthorst MM, Bartels CC, Kriege M, van Geel AN, Crepin CM, Blom JC, Meijers-Heijboer H, Klijn JG (2006) Survival and prognostic factors in BRCA1-associated breast cancer. Ann Oncol 17: 391-400.

Broeks A, Braaf LM, Huseinovic A, Nooijen A, Urbanus J, Hogervorst FB, Schmidt MK, Klijn JG, Russell NS, van Leeuwen FE, 't Veer LJ (2007) Identification of women with an increased risk of developing radiationinduced breast cancer: a case only study. Breast Cancer Res 9: R26.

Broeks A, de Witte L, Nooijen A, Huseinovic A, Klijn JG, van Leeuwen FE, Russell NS, van't Veer LJ (2004) Excess risk for contralateral breast cancer 
in CHEK $2{ }^{*} 1100$ delC germline mutation carriers. Breast Cancer Res Treat 83: 91-93.

Cybulski C, Wokolorczyk D, Jakubowska A, Huzarski T, Byrski T, Gronwald J, Masojc B, Deebniak T, Gorski B, Blecharz P, Narod SA, Lubinski J (2011) Risk of breast cancer in women with a CHEK2 mutation with and without a family history of breast cancer. J Clin Oncol 29: 3747-3752.

de Bock GH, Mourits MJ, Schutte M, Krol-Warmerdam EM, Seynaeve C, Blom J, Brekelmans CT, Meijers-Heijboer H, van Asperen CJ, Cornelisse CJ, Devilee P, Tollenaar RA, Klijn JG (2006) Association between the $\mathrm{CHEK} 2^{\star} 1100 \mathrm{delC}$ germ line mutation and estrogen receptor status. Int J Gynecol Cancer 16(Suppl 2): 552-555.

de Bock GH, Schutte M, Krol-Warmerdam EM, Seynaeve C, Blom J, Brekelmans CT, Meijers-Heijboer H, van Asperen CJ, Cornelisse CJ, Devilee P, Tollenaar RA, Klijn JG (2004) Tumour characteristics and prognosis of breast cancer patients carrying the germline CHEK2*1100delC variant. J Med Genet 41: 731-735.

Graeser MK, Engel C, Rhiem K, Gadzicki D, Bick U, Kast K, Froster UG, Schlehe B, Bechtold A, Arnold N, Preisler-Adams S, Nestle-Kraemling C, Zaino M, Loeffler M, Kiechle M, Meindl A, Varga D, Schmutzler RK (2009) Contralateral breast cancer risk in BRCA1 and BRCA2 mutation carriers. J Clin Oncol 27: 5887-5892.

Haffty BG, Harrold E, Khan AJ, Pathare P, Smith TE, Turner BC, Glazer PM, Ward B, Carter D, Matloff E, Bale AE, Alvarez-Franco M (2002) Outcome of conservatively managed early-onset breast cancer by BRCA1/2 status. Lancet 359: 1471-1477.

Hollestelle A, Wasielewski M, Martens JWM, Schutte M (2010) Discovering moderate-risk breast cancer susceptibility genes. Curr Opin Genet Dev 20: 268-276.

Jekimovs CR, Chen X, Arnold J, Gatei M, Richard DJ, Spurdle AB, Khanna KK, Chenevix-Trench G (2005) Low frequency of CHEK2 1100delC allele in Australian multiple-case breast cancer families: functional analysis in heterozygous individuals. $\mathrm{Br} \mathrm{J}$ Cancer 92: 784-790.

Kilpivaara O, Laiho P, Aaltonen LA, Nevanlinna H (2003) CHEK2 1100delC and colorectal cancer. J Med Genet 40: e110.

Kleinbaum DG, Klein M (2005) Survival Analysis. Springer: New York, USA.

Kriege M, Seynaeve C, Meijers-Heijboer H, Collee JM, Menke-Pluymers MB, Bartels CC, Tilanus-Linthorst MM, Blom J, Huijskens E, Jager A, van den OA, van Geel B, Hooning MJ, Brekelmans CT, Klijn JG (2009) Sensitivity to first-line chemotherapy for metastatic breast cancer in BRCA1 and BRCA2 mutation carriers. J Clin Oncol 27: 3764-3771.

Meijers-Heijboer H, van den Ouweland A, Klijn J, Wasielewski M, De Snoo A, Oldenburg R, Hollestelle A, Houben M, Crepin E, Veghel-Plandsoen M, Elstrodt F, van Duijn C, Bartels C, Meijers C, Schutte M, McGuffog L, Thompson D, Easton D, Sodha N, Seal S, Barfoot R, Mangion J, Chang-Claude J, Eccles D, Eeles R, Evans DG, Houlston R, Murday V, Narod S, Peretz T, Peto J, Phelan C, Zhang HX, Szabo C, Devilee P, Goldgar D, Futreal PA, Nathanson KL, Weber B, Rahman N, Stratton MR (2002) Low-penetrance susceptibility to breast cancer due to $\operatorname{CHEK} 2\left(^{*}\right) 1100 \mathrm{delC}$ in noncarriers of BRCA1 or BRCA2 mutations. Nat Genet 31: 55-59.

Mellemkjaer L, Dahl C, Olsen JH, Bertelsen L, Guldberg P, Christensen J, Borresen-Dale AL, Stovall M, Langholz B, Bernstein L, Lynch CF, Malone KE, Haile RW, Andersson M, Thomas DC, Concannon P, Capanu M, Boice JD, Bernstein JL (2008) Risk for contralateral breast cancer among carriers of the CHEK2*1100delC mutation in the WECARE Study. Br J Cancer 98: 728-733.

Metcalfe K, Lynch HT, Ghadirian P, Tung N, Olivotto I, Warner E, Olopade OI, Eisen A, Weber B, McLennan J, Sun P, Foulkes WD, Narod SA (2004) Contralateral breast cancer in BRCA1 and BRCA2 mutation carriers. J Clin Oncol 22: 2328-2335.

Nagel JHA, Peeters JK, Smid M, Sieuwerts AM, Wasielewski M, de Weerd V, Trapman-Jansen AMAC, van den Ouweland A, Bruggenwirth H, van IJcken WFJ, Klijn JGM, van der Spek PJ, Foekens JA, Martens JWM Schutte M, Meijers-Heijboer H (2012) Gene expression profiling assigns CHEK2 1100delC breast cancers to the luminal intrinsic subtypes. Br Cancer Res Treat 132: 439-448.

Nevanlinna H, Bartek J (2006) The CHEK2 gene and inherited breast cancer susceptibility. Oncogene 25: 5912-5919.

Pierce LJ, Levin AM, Rebbeck TR, Ben-David MA, Friedman E, Solin LJ, Harris EE, Gaffney DK, Haffty BG, Dawson LA, Narod SA, Olivotto IA, Eisen A, Whelan TJ, Olopade OI, Isaacs C, Merajver SD, Wong JS,
Garber JE, Weber BL (2006) Ten-year multi-institutional results of breast-conserving surgery and radiotherapy in BRCA1/2-associated stage I/II breast cancer. J Clin Oncol 24: 2437-2443.

Reding KW, Bernstein JL, Langholz BM, Bernstein L, Haile RW, Begg CB, Lynch CF, Concannon P, Borg A, Teraoka SN, Torngren T, Diep A, Xue S, Bertelsen L, Liang X, Reiner AS, Capanu M, Malone KE, Group WCS (2010) Adjuvant systemic therapy for breast cancer in BRCA1/BRCA2 mutation carriers in a population-based study of risk of contralateral breast cancer. Breast Cancer Res Treat 123: 491-498.

Riaz M, EMJJ Berns, Sieuwerts AM, Ruigrok-Ritstier K, de Weerd V, Groenewoud A, Uitterlinden AG, Look MP, Klijn JGM, Sleijfer S, Foekens JA, Martens JWM (2012) Correlation of breast cancer susceptibility loci with patient characteristics, metastasis-free survival, and mRNA expression of the nearest genes. Breast Cancer Res Treat 133: 843-851.

Robson M, Svahn T, McCormick B, Borgen P, Hudis CA, Norton L, Offit K (2005) Appropriateness of breast-conserving treatment of breast carcinoma in women with germline mutations in BRCA1 or BRCA2: a clinic-based series. Cancer 103: 44-51.

Roeb W, Higgins J, King MC (2012) Response to DNA damage of CHEK2 missense mutations in familial breast cancer. Hum Mol Genet 21: 2738-2744.

Schmidt MK, Tollenaar RA, de Kemp SR, Broeks A, Cornelisse CJ, Smit VT, Peterse JL, van Leeuwen FE, van't Veer LJ (2007) Breast cancer survival and tumor characteristics in premenopausal women carrying the CHEK $2{ }^{*} 1100$ delC germline mutation. J Clin Oncol 25: 64-69.

Sodha N, Bullock S, Taylor R, Mitchell G, Guertl-Lackner B, Williams RD, Bevan S, Bishop K, McGuire S, Houlston RS, Eeles RA (2002) CHEK2 variants in susceptibility to breast cancer and evidence of retention of the wild type allele in tumours. Br J Cancer 87: 1445-1448.

The CHEK2 Breast Cancer Case-Control Consortium (2004) $\mathrm{CHEK}^{*} 1100$ delC and susceptibility to breast cancer: a collaborative analysis involving 10,860 breast cancer cases and 9065 controls from 10 studies. Am J Hum Genet 74: 1175-1182.

The CHEK2-Breast Cancer Consortium (2002) Low-penetrance susceptibility to breast cancer due to CHEK2*1100delC in noncarriers of BRCA1 or BRCA2 mutations. Nat Genet 31: 55-59.

Tung N (2011) Management of women with BRCA mutations: a 41-year-old woman with a BRCA mutation and a recent history of breast cancer. JAMA 305: 2211-2220.

Tung N, Silver DP (2011) Chek2 DNA damage response pathway and inherited breast cancer risk. J Clin Oncol 29: 3813-3815.

van der Kolk DM, de Bock GH, Leegte BK, Schaapveld M, Mourits MJE, de Vries J, van der Hout AH, Oosterwijk JC (2010) Penetrance of breast cancer, ovarian cancer and contralateral breast cancer in BRCA1 and BRCA2 families: high cancer incidence at older age. Br Cancer Res Treat 124: 643-651.

Weischer M, Bojesen SE, Ellervik C, Tybjaerg-Hansen A, Nordestgaard BG (2008) CHEK2*1100delC genotyping for clinical assessment of breast cancer risk: meta-analyses of 26,000 patient cases and 27,000 controls. J Clin Oncol 26: 542-548.

Weischer M, Nordestgaard BG, Pharoah P, Bolla MK, Nevanlinna H, Van't Veer LJ, Garcia-Closas M, Hopper JL, Hall P, Andrulis IL, Devilee P, Fasching PA, Anton-Culver H, Lambrechts D, Hooning M, Cox A, Giles GG, Burwinkel B, Lindblom A, Couch FJ, Mannermaa A, Grenaker Alnaes G, John EM, Dork T, Flyger H, Dunning AM, Wang Q, Muranen TA, van Hien R, Figueroa J, Southey MC, Czene K, Knight JA, Tollenaar RA, Beckmann MW, Ziogas A, Christiaens MR, Collee JM, Reed MW, Severi G, Marme F, Margolin S, Olson JE, Kosma VM, Kristensen VN, Miron A, Bogdanova N, Shah M, Blomqvist C, Broeks A, Sherman M, Phillips KA, Li J, Liu J, Glendon G, Seynaeve C, Ekici AB, Leunen K, Kriege M, Cross SS, Baglietto L, Sohn C, Wang X, Kataja V, Borresen-Dale AL, Meyer A, Easton DF, Schmidt MK, Bojesen SE (2012) CHEK $2 * 1100$ delC heterozygosity in women with breast cancer associated with early death, breast cancer-specific death, and increased risk of a second breast cancer. J Clin Oncol 30: 4308-4316.

This work is published under the standard license to publish agreement. After 12 months the work will become freely available and the license terms will switch to a Creative Commons AttributionNonCommercial-Share Alike 3.0 Unported License. 